\title{
LA CASA DEL MUSEO (1972-1980): UNA COMUNIDAD DE PRÁCTICA EN CLAVE FEMENINA
}

\author{
- LETICIA PÉREZ CASTELLANOS \\ http://orcid.org/0000-0001-7396-6234 \\ Universidad Autónoma Metropolitana, Iztapalapa
}

RESUMEN La Casa del Museo fue un proyecto experimental museológico desarrollado por el Museo Nacional de Antropología (MNA) durante los setenta, para llevar parte de sus exposiciones y actividades a colonias de la entonces periferia de la Ciudad de México. El "núcleo duro" de su historia ha dado protagonismo a su creador, el museógrafo mexicano Mario Vázquez Ruvalcaba a la vez sobresalen importantes figuras masculinas que asesoraron el proyecto, "los ideólogos"; sin embargo, una amplia investigación conducida mediante el método de la etnografia multilocal que incluyó un enfoque biográfico, pone en evidencia el papel central que tuvieron las profesionistas mujeres involucradas en este proyecto, quienes también lo dotaron de contenidos y sentidos durante sus ocho años de operación. En este artículo se expone en qué consistió el proyecto, la problematización de una historia sesgada basada en pocas fuentes, el método utilizado en la investigación, así como sus resultados. Estos develan un proyecto que conformó una comunidad de práctica principalmente en clave femenina, configurando las identidades de quienes le dieron forma a través de su participación.

Palabras clave: Comunidad de práctica. Acción cultural extramuros. Identidad. Etnografía multilocal. Casa del Museo.

\section{ABSTRACT LA CASA DEL MUSEO (1972-1980) A COMMUNITY PRACTICE IN A FEMININE KEY}

La Casa del Museo was an experimental museological project developed by the MNA (National Museum of Anthropology) during the seventies, to bring part of its exhibitions and activities to neighborhoods in the then periphery of Mexico City. The "hard core" of its history has given prominence to its creator, the Mexican museographer Mario Vázquez Ruvalcaba; at the same time, important male figures who advised the project, "the ideologues" stand out; however, extensive research conducted through the method of multi-local ethnog- 
raphy that included a biographical approach, highlights the central role played by female professionals involved in this project, who also provided it with content and meanings during its eight years of operation. This article narrates what the project consisted of, the problems of a biased history based on few sources, the method used in the research, as well as its results. These reveal a project that formed a community of practice mainly in feminine key, configuring the identities of its participants through their participation.

Keywords: Community of practice. Outreach. Identity. Multi-Sited Ethnography. Casa del Museo.

\section{RESUMO A CASA DO MUSEU (1972-1980): UMA COMUNIDADE DE PRÁTICA EM CHAVE FEMININA}

A Casa do Museu foi um projeto experimental museológico desenvolvido pelo Museu Nacional de Antropologia (MNA) durante os anos 1970, com a finalidade de levar parte de suas exposições e atividades até bairros da periferia da Cidade do México. O "núcleo duro" de sua história deu protagonismo a seu criador, o museólogo Mario Vazquez Ruvalcaba que acabou se destacando ao lado de outras figuras masculinas que asessoraram este projeto, como os seus ideólogos; no entanto a partir de uma ampla pesquisa conduzida por meio do método da etnografia multilocal que incluiu um enfoque biográfico, revelou o papel central das mulheres envolvidas neste projeto que também lhe deram conteúdos e sentidos durante os oito anos de sua existência. Neste artigo são revelados em que consistiu este projeto, a problematização da sua história tendenciosa baseada em poucas fontes, o método utilizado na pesquisa, assim como os seus resultados. Estos ressaltam um projeto que revelou uma comunidade de prática de atuação feminina, configurando as identidades de aqueles que a conformaram através de sua participação.

Palavras-chave: Comunidade de prática. Ação cultural extramuros. Identidade. Etnografia multilocal. Casa do Museu.

\section{Introducción}

La Casa del Museo fue un proyecto museológico experimental desarrollado por el Museo Nacional de Antropología (MNA) de 1972 a 1980, para llevar parte de sus exposiciones y actividades a colonias de la entonces periferia de la Ciudad de México. Esta actividad significó trasladar su acción cultural más allá de sus paredes, desarrollando una serie de metodologías y prácticas poco experimentadas hasta entonces, en el seno de este museo de corte tradicional.

A pesar de que se trata de un proyecto fundante de la museología participativa (PÉREZ RUIZ, 2008), comunitaria (ANTÚNEZ, 1997; INAH, 
1989) y se postula que también de la nueva museología en Latinoamérica (ARROYO, 2007; BERG TRINIDADE DE OLIVEIRA, 2015; BRULON SOARES, 2015; BRUNO OLIVEIRA; ICOM-BRASIL, 2010; VARINE-BOHAN DE, 2008), desconocíamos detalles sobre su historia, agentes participantes, desarrollo, prácticas y destino final.

En el contexto mexicano, este proyecto ha pasado a la posteridad por tradición oral difundida entre los profesionales de museos, quienes lo sitúan predominantemente ligado a la figura del museógrafo mexicano Mario Vázquez Rubalcava (1923-2020); pero poco se ha abordado en investigaciones que trasciendan el tono anecdótico de varios artículos escritos por sus protagonistas (ANTÚNEZ, 1997, 2014; ARROYO, 1987; ORDOÑEZ GARCÍA, 1975). Aunque otros autores han retomado el tema', la mayoría remite a la información vertida por Coral Ordoñez (1975) -coordinadora en campo del proyecto-, o bien a la información incluida en la tesis doctoral Claims and Reality of New Museology: Case Studies in Canada, the United States and Mexico (HAUENSCHILD, 1988).

Esta escasez de fuentes y repetición de información condujo a pensar que no podríamos conocer más sobre este proyecto, ya que "en vista de su carácter experimental y las problemáticas que enfrentó, resulte dificil formarse una idea precisa que medie entre el olvido y la historia heroica." (SABIDO SÁNCHEZ-JUÁREZ, 2014, p. 47). Sin embargo, en 2014 la producción de un número especial de una revista dedicado a Vázquez (BEDOLLA; FÉLIX Y VALENZUELA,

1 Estos incluyen: el recuento de experiencias de vinculación museo-sociedad (BEDOLLA, 2010), la revisión del papel social del museo (VÁZQUEZ OLVERA, 2008), el análisis de la trayectoria de Mario Vázquez (SABIDO SÁNCHEZ-JUÁREZ, 2014), el desarrollo de los museos a nivel internacional (BOLAÑOS, 2002; HUDSON, 1977), la historia del ICOM México (RICO MANSARD; SÁNCHEZ MORA, 2000).

2 Es la única investigación de corte académico sobre La Casa del Museo, sus fuentes fueron entrevistas con dos colaboradoras del equipo de trabajo y el análisis de algunos documentos o informes de trabajo del proyecto.
2014), nos condujo al hallazgo del archivo del proyecto, ahora formalmente constituido en un fondo documental del archivo histórico del MNA $^{3}$.

Este fue el arranque de un estudio doctoral de antropología histórica ${ }^{4}$ para analizar las prácticas museales extramuros y resignificar parte de la historia contada a partir de un "núcleo duro" que frecuentemente da protagonismo a su creador y destaca el papel de figuras masculinas asesoras del proyecto. La investigación, conducida mediante el método de la etnografia multilocal (MARCUS, 2001) que incluyó un enfoque biográfico (WENGRAF, 2001), puso en evidencia el papel central que tuvieron las profesionistas mujeres involucradas en este proyecto quienes también lo dotaron de contenidos y sentidos durante sus años de operación.

\section{La Casa del Museo: un proyecto de acción cultural extramuros y su "núcleo duro"}

La Casa del Museo funcionó ocho años (19721980). Durante este tiempo un equipo trabajó en la concepción, puesta en marcha y ejecución de la idea. Quienes conformaron el proyecto querían llevar el "museo a la gente", derribando algunas de las barreras que separaban al MNA, ubicado en el Bosque de Chapultepec, de aquellas poblaciones excluidas hasta entonces. En línea con propuestas vanguardistas derivadas de la crítica museal planteada en reuniones internacionales y regionales del Consejo Internacional de Museos (ICOM) y de la

3 Archivo Histórico del Museo Nacional de Antropología (AHMNA). Fondo documental MNA, Sección Museografía, Sub sección Mario Vázquez, Colección La Casa del Museo, consistente en 54 expedientes y 5,101 elementos imagéticos (impresiones fotográficas, negativos y diapositivas). En adelante citada como "AHMNA - Colección La Casa del Museo".

4 La Casa del Museo (Ciudad de México, 1972-1980). Una etnografía multilocal sobre la acción cultural extramuros. Doctorado en Ciencias Antropológicas. Universidad Autónoma Metropolitana-Iztapalapa, Ciudad de México. En desarrollo. 
Unesco (ICOM, 1972; NASCIMENTO JR.; TRAMPE Y SANTOS, 2012) buscaban "integrar" el museo a estas comunidades promoviendo cambios positivos, fomentando distintos grados de participación (ORDOÑEZ GARCÍA, 1975).

Para ello, diseñaron y construyeron tres módulos hexagonales desmontables que uni-

Figura 1 - Diseño de los módulos de La Casa del Museo. Coral Ordoñez.

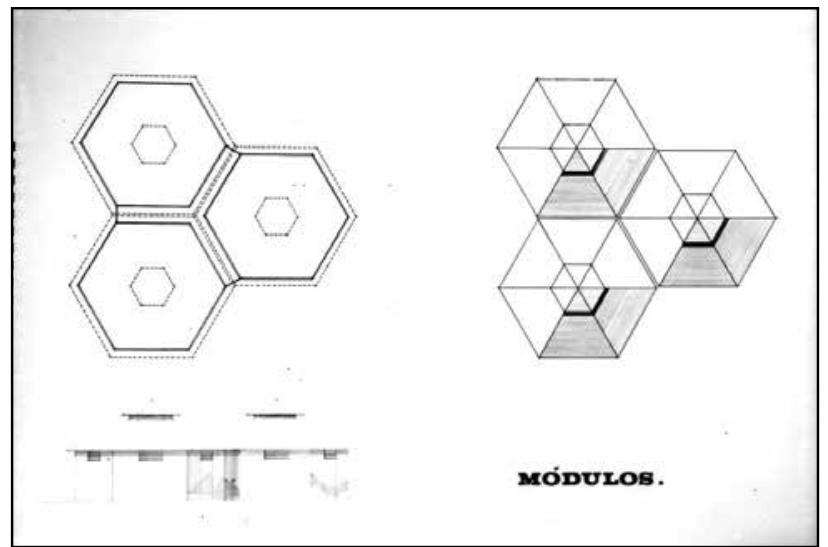

Fuente: Tomado de "The Casa del Museo, Mexico City: an experiment in bringing the museum to the people" (ORDOÑEZ GARCÍA, 1975, p. 77).

Figura 2 - Ubicació de La Casa del Museo en sus dos etapas y tres sedes.

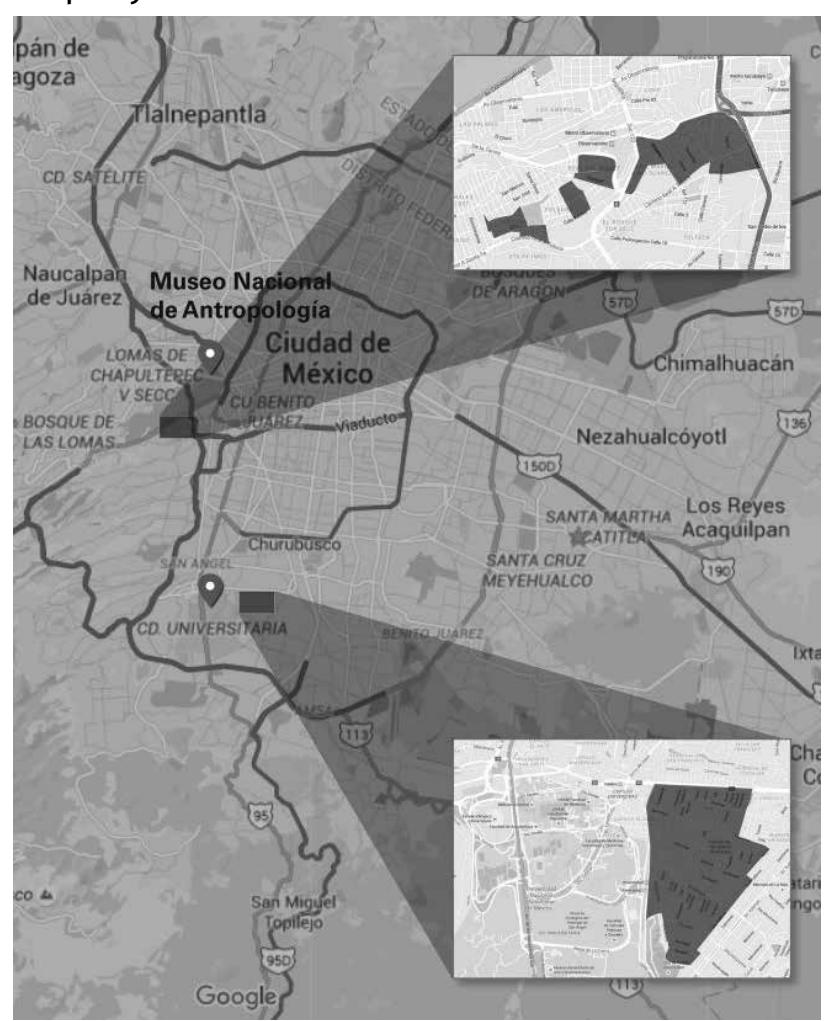

Fuente: Elaboración propia, 2020 dos integraron un espacio expositivo (Figura 1). El proyecto tuvo dos etapas: la primera en el poniente de la ciudad (Noviembre 1973-fecha indeterminada en 1976); y la segunda, con dos sedes, en la colonia Pedregal de Santo Domingo, en el sur (Febrero 1976-fecha indeterminada en 1980) (Figura 2).

El equipo de trabajo diseñó y propuso exposiciones y otras actividades complementarias desde un enfoque multidisciplinario, combinando técnicas antropológicas, herramientas de la investigación acción y de la antropología aplicada con postulados vanguardistas de la museología-equipamientos interactivos, estrategias participativas, co-diseño entre otros-. Además, llevaron a cabo un intenso trabajo social, utilizando a los estudios de públicos como parte integral para intervenir en las localidades seleccionadas, monitoréandolo y evaluándolo continuamente. Tras ocho años de trabajo, el proyecto concluyó. No existe una memoria o informe de cierre, tampoco un catálogo o publicación final.

Dado que La Casa del Museo no encaja en un tipo de museo específico, la caracterizamos como un ejemplo de acción cultural extramuros, término propuesto por quien esto suscribe definido como: la serie prácticas y procedimientos que involucran recursos humanos y materiales para poner en marcha objetivos de la política cultural, relativos al combate a la desigualdad. Estas prácticas instan a la participación cultural bajo una concepción amplia, experimentando con nuevas formas de producción cultural y apuestan por fomentar transformaciones, ya sean cambios individuales, grupales, o incluso, sociales. Son ejecutadas en espacios museales no tradicionales, fuera de las instalaciones del museo que las propone.

Aunque no hay una fecha de nacimiento de La Casa del Museo -ya que existe todo un contexto previo-, sus orígenes se remontan a 
una polémica entre Mario Vázquez, su fundador, y el sociólogo africano Stanislas Adotevi en la IX Conferencia General del ICOM (Grenoble, Francia, 1971), cuando los ponentes se enfrascaron en una discusión sobre el papel de los museos y su viabilidad en el contexto particular de los países del tercer mundo. Adotevi planteaba que los museos debían desaparecer, mientras que Vázquez opinaba que debían cambiar su orientación para hacer frente a los retos sociales (VELA CAMPOS; VELA CAMPOS, 2015).

La inconformidad de los asistentes latinoamericanos con el perfil predominantemente europeo de esa conferencia llevó a proponer una mesa redonda regional en la que se abordaran los problemas particulares de sus museos. En 1973 se celebró la Mesa Redonda sobre la importancia y el desarrollo de los museos en el mundo contemporáneo en Santiago de Chile. En las resoluciones se acordó "aceptar el ofrecimiento del Museo Nacional de Antropología de México, para experimentar la mecánica museológica del Museo Integrado a través de una exposición temporal de interés para América Latina" (NASCIMENTO JR.; TRAMPE; SANTOS, 2012, p. 79).

La exposición no vio la luz. Vázquez intuía que el público meta a quien estaría dirigida no visitaba el museo, hecho que comprobó más tarde cuando comisionó un estudio de públicos con visitantes mexicanos al MNA (GONZÁLEZ GARCíA, 1973). El resultado fue la decisión de llevar al museo fuera de sus paredes como una salida a estos debates y para poner en práctica los postulados del Museo Integral. A su regreso a México, vázquez fue "a ver a Memo Bonfil [director del INAH], platiqué con él y surgió lo de la marginalidad, y lo que implicaba ese pequeño proyecto" (VELA CAMPOS; VELA CAMPOS, 2015, p. 56). A partir de entonces se ha reproducido una historia pobre y sesgada basada en fuentes parciales. Como resultado te- nemos un "núcleo duro" (LÓPEZ AUSTIN, 2012)5: se utiliza esta idea para explicar los aspectos de la historia del proyecto que han permanecido intactos desde sus primeros recuentos, repetidos tanto en los relatos de sus protagonistas como en fuentes secundarias.

El "núcleo duro" revela varios aspectos susceptibles de reformulación, aquí nos centraremos en aquel que ha dado protagonismo a su creador y ha puesto en un lugar importante a las figuras masculinas que fungieron como asesores, opacando, $y$ a veces invisibilizando, a las protagonistas femeninas que en el día a día también lo dotaron de contenidos y sentidos. Continuando con la historia, Vázquez relata:

[...] formé un grupo integrado por el antropólogo Guillermo Bonfil, el arquitecto urbanista González Pozo, el sociólogo Raúl Benítez Zenteno, el actor Carlos Fernández; José González Márquez, músico y animador, Coral Ordóñez, arquitecta urbanista; un psicólogo que no recuerdo su nombre que trajo a su ayudante llamada Caty, el antropólogo y cineasta Alfonso Muñoz y yo como museógrafo. Teníamos reuniones para discutir la idea, el tipo de programa que pudiera tener el proyecto y qué tipo de orientación [...] (VELA CAMPOS; VELA CAMPOS, 2015, p. 156).

A este primer equipo también se incorporó el sociólogo, economista y entusiasta de las artes visuales Sergio de la Peña ( $t$ ).

La duración del proyecto, su carácter experimental, la conformación del equipo de trabajo, las tareas realizadas y las negociaciones del significado individual y colectivo de sus participantes, fueron más complejas de lo que se muestra a primera vista. La investigación conducida sacó a la luz a otras participantes y mostró que las tareas cotidianas requeridas para operar la Casa del Museo fueron realizadas mayoritariamente en clave femenina.

5 En su análisis de las tradiciones mesoamericanas el autor se refiere a los elementos más antiguos y menos susceptibles al cambio, aunque lo aplica a fenómenos de la larga duración, es de utilidad para caracterizar las partes inamovibles de la historia de La Casa del Museo. 


\section{Etnografía multilocal y perspectiva biográfica}

El análisis de La Casa del Museo implicó un trabajo de localización y construcción de fuentes para el que adoptamos el método de la etnografía multilocal (MARCUS, 2001). Por un lado, contábamos con las fuentes primarias de archivo (Colección La Casa del Museo), y por otro, con una buena diversidad de fuentes secundarias; pero, abordar este complejo proyecto de una forma más amplia y crítica incluyó realizar trabajos de campo en las localidades en donde se ubicó y entrevistar a los agentes de la producción cultural profesional y de la participación cultural social ${ }^{6}$ para así poder identificar sus prácticas y los sentidos que les atribuyen.

En la etnografía multilocal el trabajo sale de los lugares y situaciones locales, al examinar la circulación de significados, objetos e identidades culturales en un tiempo-espacio difuso (MARCUS, 2001, p. 111). Esta idea va en línea con las concepciones que adoptan una visión del campo nueva y amplia, superando la del encuentro cara a cara e incluyendo nuevos espacios de análisis como los archivos (DES CHENE, 1997). Como parte de este método integrado para mapear una práctica también utilizamos el método de entrevista interpretativo biográfico (Biographic Narrative Interpretative Method -BNIM) (WENGRAF, 2001), complementado con entrevistas con apoyo de imagen Photo-elicited interviews- (SERRANO; REVILLA; ARNAL, 2016).

El método BNIM permite al investigador "considerar tanto los contextos y condiciones conscientes e inconscientes de una acción, como las consecuencias observadas y no observadas de dicha acción" (WENGRAF, 2001, p.

6 En el marco de la investigación doctoral proponemos el marco analítico de la participación cultural holística, compuesta por la interrelación de la producción cultural profesional y la participación cultural social en las dimensiones de: acceso y disfrute, producción, representación y poder de decisión.
118). Las entrevistas iniciaron con una pregunta abierta para detonar una narración contada de acuerdo con el 'sistema de relevancia' propio del entrevistado: "cuéntame, de manera general, cómo fue tu participación en La Casa del Museo, tal como lo recuerdas" (Idem, 2001, p. 118). La estrategia consistió en ir desde los repertorios más abiertos, expresados en los términos de los entrevistados tanto como fuera posible, para después profundizar con preguntas de una guía semi estructurada.

Realizamos entrevistas con seis agentes de la producción cultural profesional -motivo de este artículo-, entre ellos, el director del proyecto con noventa y cuatro años y cinco mujeres rondando los setenta años, quienes formaron parte del equipo en distintas etapas. Las preguntas específicas de las entrevistas de profundización ahondaron en su contexto personal, sus recuerdos sobre otras personas, la relación del proyecto con otras instancias y la respuesta de los públicos. Después de tener una o hasta cuatro sesiones con cada uno, tuvimos otras adicionales para revisar las fotografias. La estrategia de contacto continuo y reiterado mejoró el raport, permitió detonar recuerdos adicionales y crear nuevas y diversas capas de significado en la construcción del "yo recordado" (BRUNER, 1994, p. 41). Esto se tradujo en varias horas de grabación, notas de campo y transcripciones de un total de veintitrés sesiones.

Estos recuentos forman parte de la memoria episódica, entendida como recuerdos de eventos singulares en la vida de una persona, lo que recuerda haber sentido, pensado, visto o hecho; las experiencias vividas son vistas a través de las perspectivas individuales y mediadas por la identidad personal (ANDERSON; GOSSELIN, 2008, p. 3). No es el evento en sí mismo sino lo que se recuerda de éste (rehearsal), el cómo se reconstruye desde el presente filtrado por toda la serie de experiencias 
transcurridas entre el momento que se rememora y el actual (ANDERSON, 2003; ANDERSON; STORKSDIECK; SPOCK, 2007).

Se trata de recuerdos instalados en la memoria del largo plazo calificada como contingente, evolutiva, subjetiva y reconfigurada por las experiencias subsecuentes (ANDERSON; GOSSELIN, 2008, p. 3); además de selectiva, colectiva y heredada, que se configura como una respuesta a las demandas del presente (VASCONCELLOS; WETZEL, 2019). No constituyen fragmentos diseccionados del pasado o evidencias sino construcciones reelaboradas desde la actualidad.

En no pocas ocasiones, él y las entrevistadas expresaron su preocupación por no ser precisos, por olvidar partes de la historia, detalles o causas. Sin embargo, las experiencias detonadas develaron episodios individuales, colectivos y de pertenencia no solo a un equipo de trabajo, sino a una comunidad de práctica (WENGER, 2001).

\section{(Re)configuración del equipo de trabajo}

Retomemos el hilo de la historia de La Casa del Museo para mostrar cómo se fueron entretejiendo los itinerarios del y las involucradas y cómo es que su trabajo cotidiano en la práctica conformó y dotó de sentido a La Casa del Museo, tanto como ésta influyó en sus trayectorias e identidades, configurándose mutuamente.

El grupo de asesores dio forma a las ideas iniciales del proyecto, pero tenían que conseguir un equipo operativo "estaba Bonfil como antropólogo, pero con su cargo no era posible" (MV, 12/10/17). Hacia junio y julio de 1972, con presupuesto asignado, Vázquez comenzó a buscar a las personas idóneas. La primera en incorporarse fue Coral Ordoñez $(t)$, por recomendación de su profesor el arquitecto Del
Pozo. Hija de refugiados españoles nacida en México, estudió arquitectura en la Universidad Nacional Autónoma de México (UNAM) y maestría en urbanismo en Bélgica, fue una de las profesionales clave para La Casa del Museo, su coordinadora en campo, la diseñadora de los módulos para la sede y quien comenzó a configurar su carácter femenino. También es la autora de una bitácora ilustrada de 65 fojas en la que narra la historia del proyecto7.

El equipo asesor recomendó integrar un equipo multidisciplinario, por ello Ordoñez invitó a la antropóloga Lilia González, con quien había trabajado previamente. A este primer grupo se unió por un breve tiempo la psicóloga Karin Wriedt. Aunque también se integraron otros profesionistas hombres, Vázquez delegó gran parte de la responsabilidad en Ordoñez y González “[...] ella trabajaba en lo suyo, yo trabajaba en lo mío, luego nos salíamos al campo, a hacer trabajo de campo, y levantábamos y hacíamos, y yo empecé a escribir y ella empezó a diseñar, pero la verdad con muchas dificultades [...]" (LGG, 19/01/19).

Durante quince meses las actividades giraron en torno a: decidir el lugar sede, realizar negociaciones y solicitar los permisos necesarios, diseñar e instalar los módulos, llevar a cabo investigaciones antropológicas previas, investigar, desarrollar y producir la primera exposición: "Donde vives. La Ciudad de México" (Noviembre, 1973). Con el espacio museal abierto se allegaron más personal para conformar un equipo estable. Aunque no había puestos definidos, la estructura de La Casa del Museo se configuró en torno a su dirección (Mario Vázquez), la coordinación (Coral Ordoñez), la investigación -principalmente antropológica(puesto ocupado, primero por Lilia González, parcialmente por Karin Wriedt y, después, por Catalina Denman), la administración (Cristi-

7 AHMNA - Colección La Casa del Museo, Expediente 54, documento 1, 68 fojas. Sin fecha. 
na Antúnez), la promoción y difusión (Miriam Arroyo y Margarito Mancilla); además del diseño museográfico, tarea alternada entre Vázquez y Ordoñez. Guillermo Bonfil $(t)$, director del INAH continuó dando su apoyo, así como los otros asesores, aunque en reuniones y con tareas cada vez más esporádicas.

\section{Las "chicas" de La Casa del Museo: una comunidad de práctica}

Las entrevistas detonaron relatos sumamente personales, en los que se entrecruzan aspectos de las identidades socio culturales de él y las participantes, detalles sobre etapas de su vida, intereses y ocupación, pero también otros aspectos anecdóticos a los que no le conferían importancia, que se entretejen con sus trayectorias de vida y profesionales: cuentan quiénes eran al momento de incorporarse al proyecto, cómo fue su participación, las relaciones interpersonales entre los miembros del equipo, sus encuentros con los públicos y lo que pasó en sus vidas cuando se separaron del proyecto. Las entrevistas con apoyo de imagen les permitieron profundizar en aspectos que no recordaban o incluso encontrar "evidencias" para algunos de sus relatos previos.

Este proyecto contribuyó a formar sus identidades. A las integrantes mujeres las llevó a identificarse y ser identificadas en el MNA como "las chicas de La Casa del Museo" (CD, $2 / 03 / 18)^{8}$. Pensemos que el proyecto transcurrió en la década de los setenta, una época de profundos cambios sociales y culturales cuando las mujeres comenzaron a ocupar cada vez más los espacios profesionales que antes les eran vedados. En el museo nacional toda una nueva generación de profesionistas mujeres se estaban incorporando en diferentes pues-

8 Las entrevistas están referidas en el formato: Iniciales de la entrevistada/o, fecha. tos, como resultado de las reconfiguraciones sociales y económicas en el país que contaba cada vez con más egresadas de las carreras universitarias, la antropología no fue una excepción (PEÑA DE LA, 2008).

¿Qué significó haber participado en un proyecto como La Casa del Museo para los y las agentes involucradas? Desafortunadamente la muerte de Ordoñez (2012) nos impidió acceder a sus testimonios. En los relatos de las otras participantes siempre se refirieron a ella con cariño y admiración. Para Ordoñez este debió ser el proyecto más importante de su carrera profesional. Como coordinadora de La Casa del Museo tomó parte desde el inicio, fue figura central con sus conocimientos de arquitectura, urbanismo y sensibilidad por el arte, fue una líder capaz de convocar y reunir a su alrededor a las otras integrantes del equipo, y su salida fue uno de los motivos importantes para su finalización hacia 1980.

Ordoñez dejó el proyecto y el país por motivos personales: el matrimonio y formar una familia. Aun cambiando su lugar residencia continuó en contacto con las otras integrantes, especialmente con Antúnez, con quien guardó una entrañable amistad hasta su muerte (CA, 15/09/17). En Europa tuvo algunos trabajos, pero nunca de la envergadura de La Casa del Museo, incluso la difundió y la dio a conocer en Holanda, lugar donde residió hasta su muerte9.

Lilia González tenía alrededor de 24 años cuando se incorporó a La Casa del Museo. Era una joven antropóloga muy entusiasta y comprometida. Formada en la Escuela Nacional de Antropología e Historia, tomó de sus maestros un interés por la antropología urbana y aplicada "[...] para mí fue de las mejores experiencias que he tenido en mi vida" (LGG, 19/04/18).

9 Peter Van Mensch. Demolishing the museum walls: towards a 'liquid museum', Tercer Congreso Internacional El Patrimonio Cultural y las Nuevas Tecnologías. Herramientas y Lenguajes para Museos. Ciudad de México, octubre 2016. 
Su involucramiento desde las primeras etapas la llevó a apegarse a él, al grado de guardar sentimientos encontrados por no ser reconocida y haber sido invisibilizada. Al igual que con Ordoñez, los motivos personales y de género pesaron en las decisiones que tomó, después de haberse casado y con un embarazo de alto riesgo, optó por renunciar al proyecto y cuidar la gestación de su primer hijo a inicios de 1975. Después se incorporó como docente a una de las universidades públicas de la Ciudad de México de la UNAM impartiendo clases en la licenciatura de sociología.

Aunque su tiempo de incorporación en el proyecto fue breve, Karin Wriedt dice que, “[...] sí marcó mí vida, y sigue presente, aunque no sé exactamente, la sala, el museo (MNA), [no tanto como para] replicarlo, sino que introyectamos todos los que estuvimos ahí, toda una parte de identidad, y que en mi caso sí lo expreso en mis clases de la Facultad de Psicología". Para ella este breve paso por La Casa del Museo se intercaló con su experiencia como guía en el museo y con una cercanía con Vázquez quien “[...] sí ha sido una persona, junto con este trabajo, primero en las guías y sobre todo este proyecto, que seguramente es una de las cosas que me han marcado en mi vida" (KW, 18/04/18).

Otra de las integrantes, Miriam Arroyo, de origen guatemalteco era un poco mayor que González, llegó por su recomedacion hacia finales de 1974 cuando La Casa del Museo estaba en marcha. Este trabajo se cruzó en su trayectoria personal ya siendo madre, haber dado prioridad a sus embarazos y a pasar los primeros años con sus hijos la llevaron a rechazar una oferta anterior en el mismo museo (MA, 18/07/17). Con estudios de educadora, llegó porque se requería alguien con experiencia para trabajar con los niños, fue una de las integrantes que permaneció por más tiempo. Cuando el proyecto acabó, Arroyo regresó al
Museo Nacional de Antropología "a cerrar la experiencia" con un estudio de público para identificar qué tantas repercusiones tuvieron las acciones extramuros en el perfil de los visitantes del museo (ARROYO, 1981).

Cristina Antúnez tuvo una larga trayectoria en la administración cultural, antes y después de La Casa del Museo, a la que pidió incorporarse por interés propio. A pesar de reiterar que se trató de un proyecto muy importante, en nuestras entrevistas restaba relevancia a su papel. La admiración, amistad y respeto que tiene por Vázquez la llevan a atribuirle gran parte del crédito y a minimizar su contribución. No obstante, señala "fue un parteaguas en la vida del antes y el después, de La Casa del Museo" y "hay otras muchas cosas que, que las traigo en la piel, sí porque te digo fueron como tatuajes... el haber tenido esa oportunidad" (CA, 15/09/18). Antúnez también permaneció en el proyecto hasta su finalización: con Arroyo presentó una ponencia en la Conferencia General del ICOM de la Ciudad de México (ANTÚNEZ; ARROYO, 1980).

En cuanto a Catalina Denman, su colaboración con La Casa del Museo duró menos en comparación con la de Ordoñez, Arroyo y Antúnez; el proyecto ayudó a afianzar los intereses que siempre tuvo en torno al tema de salud "desde que me formé como antropóloga" (CD, $2 / 03 / 18$ ) y a configurar un capital cultural estableciendo redes profesionales que le sirvieron más adelante. Trabajando temas de salud en las actividades y exposiciones de La Casa del Museo conoció a personas clave en su desarrollo, adquirió una perspectiva social que "[...] es una línea permanente, como un compromiso permanente en mi trabajo de profesionista [...]" (CD, 2/03/18).

El profesor normalista Margarito Mancilla $(\dagger)$ fue el único miembro masculino del equipo principal además de Vázquez. Se incorporó en una fecha no determinada durante la primera 
etapa y también permaneció hasta el final. Sus tareas estaban enfocadas a la promoción, y a las actividades y talleres para los niños "hacía de todo, talleres, excursiones, concursos, todo todos los elementos que puede hacer un profesor para hacer animación" (MV, 03/07/2019). Su papel fue importante al colaborar con las "chicas", pero su horario de medio tiempo pudo limitar sus aportes.

En cuanto a Mario Vázquez, hemos dicho que fue quien propuso la idea y quien viabilizó su realización gracias al puesto que ocupaba en el MNA y a su cercanía con el director del Instituto. Sin embargo, el proyecto no ocupa un lugar central en su identidad y en su memoria episódica. Por ejemplo, a pregunta expresa sobre cómo era un día cotidiano en La Casa del Museo respondió “No lo sé porque no fue un proyecto tan específico y único, yo tenía muchas cosas que hacer, tenía yo las exposiciones, tenía yo este museo encima. La Casa del Museo era una de las actividades" (MVR, 19/10/17). No se trataba de su actividad principal, como sí lo fue para las demás integrantes. Otro aspecto que refuerza esta interpretación es la ausencia de La Casa del Museo y de la conferencia de Grenoble en su currículum, él mismo no encuentra explicación: "No lo entiendo, no está, aquí lo traje..., no está, ¡me quedé con el ojo cuadrado!" (MVR, 19/10/17).

En este cruce de trayectorias, La Casa del Museo trascendió el espacio laboral para extender sus lazos hacia el espacio personal, dejando una profunda huella en la vida de estas mujeres y no así en la de Vázquez, ¿cómo explicar esta situación? Las fuertes asociaciones personales y profesionales sitúan al grupo como una comunidad de práctica. De acuerdo con Wenger (2001), las comunidades de práctica no equivalen necesariamente a los equipos de trabajo y tampoco significa que todo aquello que se denomina comunidad, por ejemplo, un barrio, lo es. En su propuesta la práctica se entiende como un proceso por el que podemos experimentar el mundo y nuestro compromiso con él como algo significativo, caracterizada por contar con una empresa conjunta, un compromiso muto y un repertorio compartido (WENGER, 2001, p. 75).

En estas comunidades, existe una profunda conexión entre identidad y práctica. Desarrollar una práctica exige la formación de una comunidad cuyos miembros puedan comprometerse mutuamente, y con ellos reconocerse como participantes; construir una identidad consiste en negociar los significados de nuestra experiencia de afiliación a comunidades sociales (WENGER, 2001, p. 187).

Este enfoque permite entender cómo es que la participación de las entrevistadas configuró de tal manera sus identidades al grado de señalar a La Casa del Museo como un punto de inflexión en sus vidas. Las descripciones de participación de Lilia González, Miriam Arroyo, Catalina Denman y Cristina Antúnez muestran copiosos detalles de una empresa conjunta: el proyecto en sí mismo, los ajustes y evolución que fue presentando y las tareas efectuadas en el día a día; un compromiso mutuo: realizar el trabajo en un equipo en el que "todos hacemos de todo, aprendemos y enseñamos"10; y un reportorio compartido: entre otras cosas, planteando conceptos clave como el de "museo comunitario"11, de gran influencia en el futuro desarrollo de estrategias participativas de gestión del patrimonio. Para Vázquez el proyecto no tuvo un efecto tan importante, aun cuando él lo propuso y viabilizó, su trayectoria, inicialmente configurada como la de

10 AHMNA - Colección La Casa del Museo, Expediente 54, documento 1 , foja 52 . Sin fecha.

11 Es posible señalar que una de las primeras menciones a esta idea se encuentra en uno de los textos declarativos de los objetivos de La Casa del Museo: "a través de museos (como La Casa del Museo) comunitarios, donde el acceso se facilita [...]" AHMNA - Colección La Casa del Museo, Expediente 5, documento 3, foja 21. 
un miembro pleno (WENGER, 2001, p. 193), fue cada vez más periférica al núcleo de la comunidad de práctica.

Ahora bien, las comunidades de práctica se pueden mirar desde dos ángulos a partir de "imágenes especulares la una de la otra" (WENGER, 2001, p. 188). De un lado está la práctica con sus dimensiones de significado, comunidad, aprendizaje, límites y localidades; del otro está la identidad con categorías semejantes que se traducen en experiencias negociadas, afiliación a las comunidades, trayectorias de aprendizaje, nexos de multiafiliación y relaciones entre lo local y lo global. Revisemos algunos de los aspectos ligados a la identidad en esta comunidad de práctica.

\section{Experiencias negociadas y multiafiliación}

Siguiendo a Wegner (2001), en la conformación de las comunidades de práctica, la identidad se negocia a diario por la superposición de capas y capas de participación y cosificación por medio de las cuales nuestras experiencias y su interpretación social se conforman mutuamente. Mientras que la participación funciona para describir la experiencia social de vivir en el mundo desde el punto de vista de la afiliación a comunidades sociales, la "cosificación" se remite al proceso de dar forma a la experiencia produciendo "objetos" que plasman esa experiencia en una cosa (WENGER, 2001, p. 88). Ambas acciones se unen mediante la negociación de significados para ubicar quiénes somos y estas negociaciones no están libres de conflictos, nos dice el autor.

El trabajo invisibilizado del equipo femenino, o al menos no plenamente reconocido, no solo se deriva de las fuentes del "núcleo duro", también es un hecho al que contribuyeron en mayor o menor medida las involucradas, que en varias ocasiones inhibieron su papel prota- gónico o lo matizaron ${ }^{12}$. A veces, solo después de trascurrido algún tiempo en la entrevista o en sesiones posteriores afloraron recuentos que las colocaban en el centro de la acción.

Los estudios de género han develado los fuertes mecanismos simbólicos y de poder que a lo largo de la historia han colocado a lo femenino en una posición subordinada a lo masculino, realidad no ajena en el campo de los museos (PRADOS TORREIRA; LÓPEZ RUIZ, 2017). Esta situación se denotó en la forma en la que diversos agentes involucrados en el proyecto refieren el trabajo de "las muchachas". Esta alusión se encuentra en varios recuentos de Vázquez, a veces en los propios relatos de las mujeres participantes e incluso cuando otros colaboradores se refirieron a ellas. El director de un centro cultural con el que La Casa del Museo colaboró estrechamente en la segunda etapa del proyecto rememora: "claro que me acuerdo, del antropólogo y las muchachas" (FDE, 15/08/17), implicando también una jerarquía entre lo masculino y lo femenino.

El lenguaje que usamos es de carácter patriarcal y sirve a sus intereses, está presente y forma parte de nuestros esquemas cotidianos sin que lo lleguemos a percibir (PARDO FERNÁNDEZ, 1992, p. 202). En español la norma para referir a la tercera persona del plural indica usar el masculino, no importa la diversidad de géneros que estén incluidos en lo que se alude. En la historia se utiliza el masculino generalizador que encubre realidades femeninas de importancia y distorsiona la realidad histórica, al ampliar realizaciones, logros o actividades femeninas al género masculino (PARDO FERNÁNDEZ, p. 1992).

Por ejemplo, el documental grabado sobre La Casa del Museo inicia con una escena en la que Vázquez conversa con Zenteno $(t)$ y

12 Como ejemplo se encuentra el artículo de Cristina Antúnez (2014) titulado "Al admirado y muy querido Mario Vázquez en su Casa del Museo: Lugar sagrado de las diosas de la memoria" 
con de la Peña para mostrar el planteamiento del proyecto, se trata de figuras centrales desde donde parte todo, en el diálogo se escucha "el equipo [debía estar] formado por gente de diversos intereses y disciplinas como economistas, antropólogos, sociólogos, desde luego, la parte museográfica"13, pero en las imágenes observamos a Coral Ordoñez, Lilia González y Karin Wriedt realizando las tareas de diseño, investigación y operación del espacio.

En otro documento se argumenta el estado de los museos en aquella época: "Entre los museólogos, museógrafos y otros especialistas priva en la actualidad la opinión de que los museos no cumplen con sus funciones de manera adecuada [...]"14, dando nuevamente protagonismo al género masculino. Este sesgo no está presente únicamente en las formalidades del español escrito y la norma "correcta", también lo observamos en el lenguaje de las involucradas: en la mayoría de las ocasiones, aun refiriéndose a ellas como un colectivo integrado exclusivamente de mujeres o siendo mayoría (con un solo integrante masculino en campo), lo hacen con el pronombre "nosotros".

Cuando Vázquez reclutó a este equipo, mayoritariamente conformado por mujeres y depositó su confianza en ellas, ninguna contaba con una idea clara de qué clase de proyecto desarrollarían. Con sus actividades cotidianas lo dotaron de forma y contenido negociando significados en la interacción entre participación y cosificación. Sus acciones se "cosificaron" en objetos rastreables que quedan como vestigios de aquella actividad pasada y que nos indican el papel central que tuvieron: los módulos (y su participación en la instalación de la segunda sede), la bitácora, las exposiciones -plasmadas en documentos y fotografias-,

13 Transcripción del documental La Casa del Museo, INAH-SEP, 1973. Acervo fílmico de la Cineteca Nacional.

14 AHMNA - Colección La Casa del Museo, Expediente 4, documento 1, foja 1 (ca. 1975). los métodos de promoción, la "gaviota" -un sistema modular para llevar exposiciones portátiles-, las investigaciones, las fotografias tomadas y los documentos producidos, todo ello con un carácter experimental de constante ajuste y reconfiguración: "nosotros trabajamos prueba y error, ¿no? Porque era un proyecto que tenía que estar avanzando y deteniéndose según las necesidades que el proyecto le fueran dando [...]" (CA, 15/09/17).

Todos pertenecemos a muchas comunidades de práctica, y el equipo de trabajo de La Casa del Museo no fue la excepción. En la primera etapa otros trabajadores del museo y del INAH se involucraron, ya desde la colaboración: el director del Instituto, personal del departamento jurídico, los herreros, carpinteros, los serigrafistas; o desde la resistencia: la jefa de la bodega de arqueología que se negaba a prestar obras originales para su exhibición, o los investigadores del Museo de Antropología que "no se interesaban por ese público, por esa problemática ni por la Casa del Museo" (MV, 14/02/19). Es importante reflexionar en cómo estos proyectos colaborativos terminan reduciendo los logros y trabajos de muchos implicados a un pequeño grupo, en estos desequilibrios pesan las desigualdades, no solo las de género, también de clase y jerarquía (BARBIERI, [s.d.]).

En la segunda etapa La Casa del Museo se alejó físicamente respecto a su alma máter. La nueva sede, ubicada al sur de la ciudad requería trasladarse una mayor distancia, la mayor implicación de los y las habitantes de esa colonia en las decisiones de la operación, temáticas y formatos del nuevo espacio excluyeron la colaboración de otros trabajadores del MNA, e incluso, desplazaron el de las integrantes del equipo para convertirlas en facilitadoras de los procesos y decisiones de los miembros de la participación cultural social. Ellos y ellas mayoritariamente- aprobaron usar solo uno 
de los tres módulos y dirigieron su instalación, decidieron las temáticas de las exposiciones, aportaron materiales para auto representarse, gestionaron el horario de apertura del espacio desde las cinco de la mañana, entre otras cosas.

Estas prácticas también incidieron en un desplazamiento conceptual. Inicialmente se pensaba que el MNA detentaría un mayor poder, al buscar "Incorporar a los habitantes de la comunidad [...] con el fin de lograr que con el tiempo ellos mismos se hagan cargo del museo en todos sus aspectos, contando siempre con la asesoría del M.N. de $A^{\prime \prime 15}$, pero después, la interrelación de estas dos comunidades de práctica: habitantes del Pedregal de Santo Domingo y equipo de La Casa del Museo condujo a otra situación. En palabras de Arroyo, Vázquez opinaba "se las comió la comunidad", y yo le contesté. “¿Y no queríamos eso?", porque eso fue lo que yo sentí. Así lo sentí, y entonces actué. No queríamos eso, sí eso era lo que queríamos, que fuera el museo el que llegara y se lo apropiara la gente, eso que era un elemento cultural ajeno, pero que lo hiciera propio [...]" (MA, 30/05/19).

La dimensión femenina de La Casa del Museo atraviesa otros aspectos; por ejemplo, el que ningún involucrado recuerde con precisión de dónde vino el nombre $y$, sin embargo, quienes estuvieron en esa casa -espacio tradicionalmente femenino- fueron mujeres. 0 las distintas posturas que ocasionó la presencia del equipo de mujeres en cada sede, en Observatorio detonó percepciones negativas en los públicos potenciales:

Me dijo una señora 'es que los señores sí pueden ir, pero nosotras no', ¿y por qué? 'porque ahí es una casa de mala nota', y le dije, se llama La Casa del Museo, ¿pero usted sabe que es un museo? 'No, pero mi marido dice que vio unas

15 AHMNA - Colección La Casa del Museo, Expediente 5, documento 1, fojas 3 y 4. Ca. 1977. El subrayado es nuestro. fotos'. Entonces le dije ¿usted qué cree que hay ahí? 'Ah pues ahí dice que solo hay mujeres'. Yo soy una, yo trabajo ahí, y fijese que ahí se cuenta la historia de Tacubaya [...] (MA, 20/07/17)

Por el contrario, en el Pedregal de Santo Domingo la situación fue de apoyo mutuo por las características y condiciones de la población, en donde las mujeres tuvieron un papel protagónico para conformar el barrio (DÍAZ ENCISO; POBLADORES Y FUNDADORES, 2002). Durante la instalación del módulo, una de las señoras le indicaba a Antúnez: "No Cristina, dame la cuchara, tú no le sabes', o sea era una camaradería, pero al mismo tiempo profundo respeto, por el trabajo de ellos y del nuestro" (CA, 15/09/17).

\section{Trayectorias de aprendizaje}

La identidad es un proceso de continua progresión que enhebra formas sucesivas de participación en el que cruzan las trayectorias de aprendizaje de muchas personas, las cuales pueden clasificarse como: periféricas, entrantes, de miembros, limitantes y salientes (WENGER, 2001, p. 197). No se trata de un proceso fijo ni lineal, sino de entradas y salidas, y cambios de perspectivas.

Para 1972, año de inicio del proyecto, la identidad de Vázquez estaba conformada alrededor de su yo "museógrafo" (BEDOLLA; FÉLIX Y VALENZUELA, 2014). En aquel entonces su trayectoria era la de un reconocido museógrafo, había participado en numerosos proyectos entre ellos la apertura del afamado MNA (1964). Para Vázquez cada oportunidad de implicarse en proyectos reforzó ese aspecto de su identidad profesional. En nuestras primeras charlas veía con escepticismo que La Casa del Museo pudiera ser materia para una investigación formal, o que el proyecto tuviera alguna relevancia más allá de un proyecto "bonito" hecho con "entusiasmo" (MVR, 19/10/17). No obstante, 
a lo largo de las entrevistas, y sobre todo al revisar las fotografías, llegó a revalorarlo.

Su papel central al inicio del proyecto se fue desplazando hacia la periferia de la comunidad de práctica, siempre ligado a ésta. Al inicio como su artífice, luego como la persona a quien consultaban diariamente las decisiones, ya que en su despacho de jefe de la sección de museografía alojó las "oficinas" de La Casa del Museo; luego, como subdirector del museo ya no le fue posible mantenerse tan cerca, pero continuó implicado en varios aspectos de la museografía. De este aspecto guarda recuerdos nítidos: los objetos que utilizaron, su fuente, caracteristicas, los errores cometidos: “¡Ah un maniquí con un quexquémetl! Mira qué mentirosos, el paño de misa no lo portaban así, nos equivocamos, debe ser doblado y así asentado no en forma de cucurucho" (MVR, 3/07/19).

Las otras participantes del proyecto fueron miembros plenos de la comunidad de práctica. A Coral Ordoñez, La Casa del Museo le dio una oportunidad única para poner en juego sus conocimientos de arquitecta, urbanista y su sensibilidad artística. Las antropólogas Lilia González y Catalina Denman eran jóvenes profesionistas recién egresadas de esta disciplina buscado conformar su identidad profesional. Para Lilia, La Casa del Museo fue la oportunidad de poner en la práctica los novedosos postulados de la antropología mexicana surgidos en contrapropuesta al indigenismo postrevolucionario anquilosado operado por el INAH (PEÑA DE LA, 2008). Califica su investigación como “un estudio de antropología social aplicada, es decir, cómo poder revertir esto en una exposición para que ellos mismos se vean, es decir, se vean expuestos ahí" (LGG, 19/04/18), su informe no publicado es un ejemplo pionero de antropología urbana (GONZÁLEZ GARCíA, 1975).

Denman no se desempeñó en el área de museos ni antes ni después de La Casa del Museo, pero este proyecto la puso en contacto con una temática de su interés a partir de la cual desplantó su carrera enfocada a la antropología médica y a la salud. Los ecos de La Casa del Museo llegan hasta la actualidad, como rectora del Colegio de Sonora (2003-2008): “Debí hacer más trabajo de vinculación o extensión... en general, todas nos formamos en ese proyecto, fue un proyecto de mucha formación de nosotras". Aunque los temas de salud "la jalaron", ve a los "hijos [de La Casa del Museo] por todos lados en el trabajo que yo misma sigo haciendo", piensa que al jubilarse se va "[...] a poner a trabajar un proyecto de La Casa del Museo acá en Sonora... creo que da para mucho, pero definitivamente sería con una Gaviota que traería amarrada a mi carro." (CD, 2/03/18).

Finalmente, para Arroyo, este fue el proyecto clave para su itinerario profesional hasta la actualidad. Aunque de inicio "ya lo traía" -Se refiere a una sensibilidad por lo social-, porque "yo ya venía con esa ideología [...] mi visión social siempre estuvo presente, mi interés en trabajar con la gente también [...] ahí me fui formando y fui buscando, la especialidad que hice fue en la coordinación de grupos" (MA, 25/02/19). Dedicó su vida a este trabajo, primero en La Casa del Museo, luego en el Programa para el Desarrollo de la Función Educativa de los Museos de la Coordinación Nacional de Museos y Exposiciones, desde donde impulsó la formación de museos comunitarios en varios estados del país (INAH, 1989). Le valió su incorporación al Movimiento Internacional para una Nueva Museología. Al dejar sus puestos como servidora pública fue gestora cultural independiente, actualmente trabaja en una asociación civil promoviendo proyectos de participación cultural social.

\section{Comentarios finales}

A poco más de cuarenta años del inicio de La Casa del Museo, la etnografia multilocal con- 
ducida permitió seguir distintos hilos para mapear sus prácticas y allegarnos de muchas más fuentes de las que habían estado disponibles en otras investigaciones. El hallazgo del archivo del proyecto fue el inicio de una búsqueda para proveer una caracterización empíricamente basada, histórica y descriptivamente adecuada, además de más realista de este proyecto (SOLER et al., 2014), para discutir la compleja relación entre los museos y distintos aspectos de la desigualdad, desde las perspectivas de sus agentes participantes. En este artículo hemos abordado la relativa al género.

Para ello, desde una perspectiva que fuimos construyendo y que mira a la participación cultural desde un enfoque holístico, localizamos a tantos miembros de la producción cultural profesional como fuera posible para entrevistarles utilizando un enfoque biográfico, también regresamos a las localidades en las que se ubicó el proyecto para rastrear sus huellas. En el lado de los profesionales, la participación en proyectos de acción cultural extramuros lleva a los y las colaboradoras a implicarse de maneras que rebasan los límites de los equipos de trabajo convencionales para configurarse en grupos más complejos asumiendo empresas conjuntas, compromisos mutuos y repertorios compartidos, es decir en comunidades de práctica.

En estas comunidades los miembros tienen distintos papeles, el trabajo y las actividades de distintas personas se entrecruzan en diversas trayectorias, como miembros plenos o en vertientes periféricas. Con el paso del tiempo, a falta de una mayor diversidad de fuentes, por la repetición de un "núcleo duro" el trabajo e importancia de ciertos miembros pueden ser invisibilizados.

En La Casa del Museo, esto obedece a una mezcla de factores entre los que no podemos soslayar el papel subalterno que se ha asignado a las mujeres en una cultura patriarcal.
No obstante, una documentación más amplia de las actividades en el día a día de esa casa, así como el análisis de las negociaciones del significado, sus experiencias de participación y la "cosificación" que las denota pone a las integrantes femeninas del equipo en el centro de la acción.

Si la acción cultural extramuros es una estrategia para poner en marcha objetivos de la política cultural, relativos al combate a la desigualdad, y si en La Casa del Museo se buscaba "llevar el museo a la gente" para mediar estas desigualdades, debemos considerar que la desigualdad no solo atañe a los aspectos del acceso a los museos y que no solo es materia de quiénes vienen y quiénes no. Cuando el museo sale de sus paredes, sus acciones siguen cruzadas por la desigualdad, que afecta a la participación cultural social tanto como a la producción cultural profesional (BARBIERI, [s.d.]).

Varios de los aspectos sociales estructurales, entre ellos la desigualdad de género, también se pueden observar en estos proyectos de "pequeña escala". Por ejemplo, el hecho de que las mujeres enfrenten desventajas frente a los hombres al desarrollarse en una carrera profesional en competencia con sus etapas reproductivas y sus intereses personales; también al ser invisibilizadas en el lenguaje y otros dispositivos que priorizan historias en masculino.

Aunque la participación de figuras como Vázquez, Bonfil y los otros asesores fue clave para originar y viabilizar La Casa del Museo, a ésta también la definieron sus participantes femeninas conforme la fueron configurando a través de sus jornadas de trabajo, experimentación y ajustes. Fue la respuesta negociada a su situación, les pertenecía a pesar de todas las fuerzas e influencias que escapaban a su control: bajo presupuesto, alejamiento de Vázquez, recortes presupuestales, falta de em- 
patía en el MNA, entre otras que llevaron a su finalización. Así, La Casa del Museo pervive hoy hasta en las paredes de sus casas:

"Lilia, que te recuerde esta flor para que nunca te marchites", señala una dedicatoria en una acuarela que le regaló José Luis Martínez Diez $(\dagger)$, otro de los miembros del equipo, a González "la tengo puesta, incluso en mi casa" (LG, 19/04/18).

\section{Referencias}

ANDERSON, David. Visitors' Long-Term Memories of World Expositions. Curator - The Museum Journal, v. 46, n. 4, p. 401-420, 2003. Disponible en: https:// doi.org/10.1111/j.2151-6952.2003.tb00106.x Accedido: 10 oct. 2014.

ANDERSON, David; GOSSELIN, Viviane. Private and public memories of Expo 67 a case study of recollections of Montreal's World's Fair, 40 years after the event. Museums and Society, v. 6, n. 1, p. 1-21, 2008. Disponible en: https://journals.le.ac.uk/ojs1/index. php/mas/article/view/109 Accedido: 27 mar. 2017.

ANDERSON, David; STORKSDIECK, Martin; SPOCK, Michael. Understanding the Long-Term Impacts of Museum Experiences. En: FALK, John; DIERKING, Lynn; FOUTZ, Susan. (Eds.). In principle, in practice: museums as learning institutions. Learning innovations series. Lanham: AltaMira Press, 2007. p. 197-215.

ANTÚNEZ, Cristina. La Casa del Museo: precursora de los museos comunitarios. Gaceta de Museos, n. 6, p. 1997. Disponible en: https://mediateca.inah.gob. $\mathrm{mx} /$ repositorio/islandora/object/articulo:19491 Accedido: 16 ene. 2016.

ANTÚNEZ, Cristina. Al admirado y muy querido Mario Vázquez en su Casa del Museo: Lugar sagrado de las diosas de la memoria. Gaceta de Museos, n. 60, p. 52-59, dic. 2014. Disponible en: https://www. revistas.inah.gob.mx/index.php/gacetamuseos/issue/view/423 Accedido: 24 oct. 2017.

ANTÚNEZ, Cristina; ARROYO, Miriam. Casa del Museo. En: 12th General Conference of ICOM, 1980, Ciudad de México, 1980. Inédito.
ARROYO, Miriam. Los visitantes y el funcionamiento del Museo Nacional de Antropología. Inédito, 1981.

ARROYO, Miriam. La Casa del Museo, experiencias mexicanas. Departamento de servicios educativos, museos escolares y comunitarios. INAH, Inédito, 1987.

ARROYO, Miriam. La nueva museología en México, 2007. Disponible en: <www.simuseo.net/assets/ sim3lp.pdf>. Accedido: 12 set. 2016.

BARBIERI, Nicolás. Es la desigualdad. También en la cultura. Pensamiento. Cultura y Ciudadanía. [s.f.]. Disponible en: https://www.mecd.gob.es/dam/ jcr:3419299b-4183-4a2c-9eea-433393379d9e/ Nicolas-Barbieri.pdf Accedido: 6 nov. 2018.

BEDOLLA, Ana Graciela. De museos y comunidades. Experiencias institucionales de Vinculación. Gaceta de Museos. INAH: 70 aniversario, n. 47-48, p. 20-27, 2010. Disponible en: https://www.revistas.inah.gob.mx/index.php/gacetamuseos/article/ view/1200/1156 Accedido: 16/1/2016.

BEDOLLA, Ana Graciela; FÉLIX Y VALENZUELA, Fernando. (EDS.). Mario Vázquez. Obra museológica y museográfica. México, D.F. v. 60, dic. 2014-mzo. 2015. Disponible en: http://mediateca.inah.gob.mx/repositorio/islandora/object/issue:901Accedido: 6 abr. 2017

BERG TRINIDADE DE OLIVEIRA, Patricia. Apropriações e invenções: a experiência dos museus comunitários do México (1958/1993). 2015, 185 f. Dissertação (Mestrado em Educação) - Programa de Pós-Graduação em Educação (PPG/Edu), Universidade Federal do Rio Grande do Sul (UFRGS), Porto Alegre, Brasil, 2015. Disponible en: https://www.lume.ufrgs. br/bitstream/handle/10183/117822/000968689.pdf?sequence=1 Accedido: 6 abr. 2017.

BOLAÑOS, María. La memoria del mundo: cien años de museología, 1900-2000. 1. ed. ed. Gijón (Asturias): Ediciones Trea, 2002.

BRULON SOARES, Bruno. L'invention et la réinvention de la Nouvelle Muséologie. ICOFOM Study Series, n. 43a, 2015. Disponible en: http://journals. openedition.org/iss/563 Accedido: 8 feb. 2018. 
BRUNER, John. The "Remembered" self. En: NEISSER, Ulric; FIVUSH, Robyn (Eds.). The remembering self: construction and accuracy in the self-narrative. Cambridge; New York: Cambridge University Press, 1994. p. 41-54.

BRUNO, María Cristina Oliveira. ICOM-BRASIL. 0 ICOM-Brasil e o pensamento museológico brasileiro: documentos selecionados, 2010.

DES CHENE, Mary. Locating the past. En: GUPTA, Akhil (Ed.). Anthropological locations: boundaries and grounds of a field science. Berkeley: University of California Press, 1997. p. 66-85.

DÍAZ ENCISO, Fernando; POBLADORES Y FUNDADORES. Las mil y una historias del Pedregal de Santo Domingo. Mexico: Dirección General de Culturas Populares e Indígenas del Consejo Nacional para la Cultura y las Artes, Secretaria de Cultura de la Ciudad de México, Unión de Colonos del Pedregal de Santo Domingo, Centro de Artes y Oficios "Escuelita Emiliano Zapata", 2002.

GONZÁLEZ GARCÍA, Lilia. Imagen del museo y características, opiniones y sugerencias del visitante mexicano, ene. 1973. <Archivo personal de la autora>.

GONZÁLEZ GARCÍA, Lilia. La zona de Observatorio, un estudio de población urbana de la ciudad de México, ene. 1975. <Archivo personal de la autora>.

HAUENSCHILD, Andrea. Claims and Reality of New Museology: Case Studies in Canada, the United States and Mexico. Center for Museum Studies, Smithsonian Institution. 1998. Disponible en: http://museumstudies.si.edu/claims2000.htm, Accedido: 27 out. 2014.

HUDSON, Kenneth. Museums for the 1980s. A survey of world trends. New York: Holmes \& Meier Publishers - Unesco, 1977.

ICOM. The museum in the service of man today and tomorrow. The museum's educational and cultural role. The papers from the Ninth General Conference of ICOM. Gran Bretaña: ICOM, 1972.

INAH. Departamento de Servicios Educativos, Museos Escolares y Comunitarios. Memoria, 19831988. SEP-INAH, 1989.
LÓPEZ AUSTIN, Alfredo. Cosmovisión y pensamiento indigena. En: Conceptos y fenómenos fundamentales de nuestro tiempo. Universidad Autónoma de México, Instituto de Investigaciones Sociales, 2012. Disponible en: http://conceptos.sociales.unam. $\mathrm{mx} /$ conceptos_final/495trabajo.pdf?PHPSESSID=ffc42510e755335c76404a255913b8ab Accedido: 16 jul. 2019.

MARCUS, George. Etnografia del sistema mundo. El surgimiento de la etnografía multilocal. Alteridades, v. 11, n. 22, p. 111-127, dic. 2001. Disponible em: https://alteridades.izt.uam.mx/index.php/Alte/article/view/388, Accedido: 15 jul. 2019.

NASCIMENTO JR., Jose Do; TRAMPE, Alan; SANTOS, Paula Assunção dos. Mesa Redonda sobre la Importancia y el Desarrollo de los Museos en el Mundo: Santiago de Chile, 1972. Brasília: Instituto Brasileiro de Museus, Programa Ibermuseos, 2012.

ORDOÑEZ GARCíA, Coral. The Casa del Museo, Mexico City: an experiment in bringing the museum to the people. Museum, v. XXVII, n. 2, p. 71-77, 1975. Disponible en: https://www.tandfonline.com/doi/ abs/10.1111/j.1468-0033.1975.tb01857.x Accedido: 16 ene. 2016.

PARDO FERNÁNDEZ, Alejandrina. La política lingüística del patriarcado. Política y cultura, n. 1, p. 195213, Otoño 1992. Disponible en: http:/ / www.redalyc. org/articulo.oa?id=26700114 Accedido: 10 ene 2020

PEÑA DE LA, Guillermo. La antropología social y cultural en México. Ponencia apresentado en Anthropology in Europe. Madrid, sept. 2008. Disponible en: http://pendientedemigracion.ucm.es/info/antrosim/docs/DelapenaMexico.pdf Accedido: 6 abr. 2017.

PÉREZ RUIZ, Maya Lorena. La museología participativa: ¿tercera vertiente de la museología mexicana? Cuicuilco, v. 15, n. 44, p. 87-110, 2008. Disponible en: https://www.mediateca.inah.gob.mx/islandora_74/ islandora/object/articulo\%3A15194 Accedido: 15 mar. 2020

PRADOS TORREIRA, Lourdes; LÓPEZ RUIZ, Clara. (EDS.). Museos arqueológicos y género: educando en igualdad. Madrid: Universidad Autónoma de Madrid, 2017. 
RICO MANSARD, Luisa. Fernanda; SÁNCHEZ MORA, José Luis. ICOM México: semblanza retrospectiva. México: Conaculta-Fonca, 2000.

SABIDO SÁNCHEZ-JUÁREZ, Alejandro. Tres momentos de la actividad museológica de Mario Vázquez. Gaceta de Museos, v. Tercera época, n. 60, p. 41-53, 2014. Disponible en: https://www.mediateca.inah. gob.mx/islandora_74/islandora/object/articulo\%3A12656 Accedido:15 mar. 2020.

SERRANO, Araceli; REVILLA, Juan Carlos; ARNAL, María. Narrar con imágenes: entrevistas fotográficas en un estudio comparado de "resiliencia" social y resistencia ante la crisis. EMPIRIA. Revista de Metodología de Ciencias Sociales, n. 35, p. 71-104, dic. 2016. Disponible en: https://www.redalyc.org/ pdf/2971/297147433004.pdf Accedido:16 jul. 2019.

SOLER, Lena. et al. (EDS.). Introduction. En: Science after the practice turn in the philosophy, history, and social studies of science. Routledge studies in the philosophy of science. Kindle edition ed. New York: Routledge, 2014. p. 93-113.

VARINE-BOHAN DE, Hugues. Museus e Desenvolvimento Social: balanço crítico. En: BRUNO, María Cristina Oliveira; NEVES, Kátia Regina Felipini (Eds.). Museus como agentes de mudança social e desenvolvimento: propostas e reflexões museológicas. Sergipe, Brasil: Museu de Arqueologia de Xingó, 2008. p. 11-15.
VASCONCELLOS, Camillo de Mello; WETZEL, Clarissa. Memória e Identidade nos Museus: o caso do Museu do Carvão. En: MAGALHÃES Fernando; FERREIRA DA COSTA, Lucina; HERNÁNDEZ HERNÁNDEZ, Francisca. (Eds.). Museologia e património. Brasil: Escola Superior de Educação e Ciências Sociais | Politécnico de Leiria, 2019. v. 2, p. 84-106.

VÁZQUEZ OLVERA, Carlos. Estudio introductorio. Revisiones y reflexiones en torno a la función social de los museos. Cuicuilco, v. 15, n. 44, p. 5-14, 2008. Disponible en: https://mediateca.inah.gob. $\mathrm{mx} /$ repositorio/islandora/object/articulo:15190 Accedido: 18 set. 2018.

VELA CAMPOS, María; VELA CAMPOS, Mária de los Ángeles. Charlas con la museografía. Memoria museológica y museográfica de Mario Vázquez Rubalcava. México, D.F: Rubmont Ediciones, 2015.

WENGER, Etienne. Comunidades de práctica: aprendizaje, significado e identidad. Barcelona: Paidós, 2001.

WENGRAF, Tom. Qualitative Research Interviewing: biographical narrative and semi-structured methods. London: Sage, 2001.
Recebido em: 03.02.2020

Revisado em: 15.05.2020

Aprovado em: 31.05 .2020

Leticia Pérez Castellanos es doctorante en Ciencias Antropológicas, Universidad Autónoma Metropolitana, Iztapalapa y Profesora investigadora en la Escuela Nacional de Conservación, Restauración y Museografía - "Manuel del Castillo Negrete", del Instituto Nacional de Antropología e Historia. E-mail: leticia_perez_c@encrym.edu.mx 